\title{
Developments in mechanization of root and tuber crop peeling machine
}

Ishwar Shinde, Hanuman Bobade and Sachin Patil

Received : 10.04.2018; Accepted : 13.04 .2018

See end of the Paper for authors' affiliation

Correspondence to :

Ishwar Shinde Department of Agricultural Engineering, Maharashtra Institute of Technology, Aurangabad (M.S.) India Email : shindeishwar9527@ gmail.com
- Abstract : The root and tuber crops are of immense importance with respect to their varying utility and nutritional aspects. This review is aimed at discussing the developments in mechanization of peeling systems for the root and tuber crops in food processing related industries and at house hold. The root and tuber crops are produced in significant amount in India and world. Production of ginger, potato and sweet potato in India for the year 2017-2018 was 1075 MT, 49344 MT and 1465 MT, respectively. These crops are consumed in all over world for their peculiar characteristics. These root and tuber crops are rich sources of phytochemicals and bioactive compounds which are reported to have many health benefits. Many of these root and tuber crops are covered by a protective covering or peel which in general is inedible and is of less significance in view point nutrition. Hence, before further processing or consumption usually this peel is removed. The peel is removed by many methods like manual, mechanical, thermal and chemical. Being high level of heterogeneity in the structure of root and tuber crops like ginger, potato and sweet potato peeling processes face a numerous problems. There had been considerable developments in mechanization of peeling systems, however each of these with certain shortcomings. Mechanical peeling is more efficient (75-80\%) with minimum loses, easy to operate and other advantages. This review will help in finding the pros and cons of various in mechanized peeling systems and future scope for improvement in these systems.

- Key words : Peeling, Processing, Ginger, Potato, Sweet potato

- How to cite this paper : Shinde, Ishwar, Bobade, Hanuman and Patil, Sachin (2018). Developments in mechanization of root and tuber crop peeling machine. Internat. J. Agric. Engg., 11(Sp. Issue) : 121-126, DOI: 10.15740/HAS/IJAE/11.Sp. Issue/121-126. 